\title{
A abertura procedimental da jurisdição constitucional exercida pelos órgãos de cúpula: breves notas sobre Alemanha, Brasil e EUA
}

\author{
The procedural opening of constitutional jurisdiction by the summit organs: brief notes on \\ Germany, Brazil and the U.S.A.
}

João Costa Ribeiro Neto ${ }^{1}$

\section{Resumo}

O objetivo deste trabalho é exemplificar uma tendência da Jurisdição Constitucional, mundo afora, de flexibilizar as exigências procedimentais impostas àqueles que submetem questões a um dado órgão de cúpula. Para isso, buscaramse três paradigmas: Alemanha, Brasil e EUA. A partir do estudo de algumas decisões dos órgãos de cúpula dos mencionados países, foi possível notar mudanças pelas quais institutos jurídicos vêm passando, de modo a facilitar o acesso às respectivas Cortes. No presente texto, foram estudados os seguintes institutos jurídicos, que são exemplos de abertura procedimental na Jurisdição Constitucional: na Alemanha, o Rechtsschutzbedürfnis; no Brasil, o instituto do amicus curiae e as audiências públicas; nos EUA, o mootness. $O$ estudo dos referidos institutos revela que os órgãos de cúpula dos respectivos países, ao exercerem a Jurisdição Constitucional, estão a apegar-se cada vez menos às formalidades meramente procedimentais, a fim de dar maior importância às questões constitucionais levadas ao conhecimento da Corte. Isso não significa que as Cortes Constitucionais não sejam rígidas nos critérios de submissão de casos ou, tampouco, que mais casos estejam sendo apreciados por essas Cortes, mas sim que, frequentemente, grandes controvérsias constitucionais estão sendo admitidas, embora o caso concreto que suscitou a respectiva questão já não requeira uma decisão judicial. Da mesma forma, nota-se uma constante pluralização daqueles protagonistas sociais autorizados a levar argumentos às Cortes Constitucionais.

Palavras-chave: Jurisdição constitucional. Abertura procedimental. Cortes constitucionais. Mootness. Rechtsschutzbedürfnis.

\begin{abstract}
The goal of this text is to illustrate a trend of Judicial Review, worldwide, of easing the procedural requirements imposed on those who submit questions to a given Constitutional Court. Thereunto, three examples were briefly analyzed: Germany, Brazil and the USA. The study of the highest Courts of the mentioned countries
\end{abstract}

\footnotetext{
Mestrando em Direito, Estado e Constituição pela Universidade de Brasília (UnB), sob a orientação do Ministro Gilmar Ferreira Mendes, do Supremo Tribunal Federal (STF). Mestrando em Direito Romano pela Faculdade de Direito do Largo de São Francisco/Universidade de São Paulo (USP). Bacharel (2010) e Licenciado (2011) em Filosofia pela Universidade de Brasília (UnB). Bacharel em Direito pela Universidade Católica de Brasília (UCB) (2011). Foi, durante um ano, aluno especial do Mestrado em Filosofia da Universidade de Brasília (UnB). Student Member da Society for the Promotion of Roman Studies (Fundada em 1910) e da Society for the Promotion of Hellenic Studies (Fundada em 1879). Estagiou no escritório de advocacia Simon \& Partner, em Stuttgart, na Alemanha. Atualmente, é advogado em Brasília.
} 
shows that noticeable changes have taken place in some of their legal institutions. It also indicates that this is happening in order to facilitate the access of great constitutional controversies to the Courts. In this paper, the following legal institutions, which are examples of procedural openness in the Judicial Review, were analyzed: in Germany, the Rechtsschutzbedürfnis; in Brazil, the amicus curiae and the public hearings (audiências públicas); in the U.S., the mootness. The research revealed that those highest Courts, while exerting the power of Judicial Review, are clinging less and less to purely procedural formalities in order to give greater importance to the constitutional questions brought to the attention of the Court. This does not mean that the Constitutional Courts do not use rigid criteria for the submission of cases, nor that more cases are being examined by the courts. It means, instead, that very often great constitutional controversies are being admitted, even though the case that raised the question no longer requires a Court decision. Likewise, there is also a constant trend of pluralizing the social protagonists that are allowed to take arguments before the Courts.

Keywords: Judicial review. Procedural opening. Constitutional courts. Mootness. Rechtsschutzbedürfnis.

\section{Introdução}

O presente trabalho tem por escopo mostrar como o controle de constitucionalidade exercido por alguns órgãos de cúpula tem passado por um processo de abertura procedimental. Denomina-se de abertura procedimental a flexibilização das regras formais-processuais que regem e condicionam a apreciação de uma determinada demanda. No que tange ao presente texto, observa-se uma tendência crescente de relativizar os requisitos impostos aos atores que submetem questões à apreciação dos órgãos de cúpula incumbidos do controle de constitucionalidade.

É possível notar a chamada abertura procedimental em alguns países. Buscou-se, a partir dos órgãos de cúpula da Alemanha, do Brasil e dos EUA, fornecer alguns exemplos dessa flexibilização formal.

\section{Abertura procedimental no Supremo Tribunal Federal (STF)}

O Supremo Tribunal Federal tem sido palco de uma flexibilização das regras procedimentais que condicionam a apreciação de questões submetidas ao crivo da Corte. Em diversas oportunidades, a Corte pronunciou-se no sentido de mitigar as exigências processuais impostas às partes, de modo a privilegiar a matéria constitucional suscitada. 
Não há dúvidas de que esse tipo de atitude favorece um âmbito maior de desempenho funcional para a Corte, uma vez que faz com que um maior número de controvérsias constitucionais sejam levadas ao STF.

\subsection{Os amici curiae}

A figura do amicus curiae representa, no controle de constitucionalidade hodierno, um importante instrumento de flexibilização procedimental, no que diz respeito às exigências impostas aos atores que podem provocar a atuação da Corte.

Sabe-se, por exemplo, que a Constituição Federal de 1988 prevê um rol de legitimados para ajuizar ações de controle concentrado de normas (art. 103, CF). Em tese, esse rol teria o condão de obstar a participação, no referido controle, de outros atores que nele não estejam previstos. Contudo, a magnitude das decisões tomadas pelo STF, mormente se dotadas de oponibilidade erga omnes e eficácia vinculante, fez com que o legislador permitisse, mediante decisão do relator do processo em questão, que entidades da sociedade civil levassem informações à Corte que julgassem importantes para o deslinde da questão jurídica em apreço.

Nesse contexto, os amici curiae, conforme a previsão do $\S 2^{\circ}$ do art. $7^{\circ}$ da Lei de $n$. 9.868/99, representam, institucionalmente, uma ampliação dos habilitados a discutir, perante o Supremo Tribunal Federal, a questão que se coloca diante da Corte.

Ressalte-se que a figura do amicus curiae já foi admitida em processos de controle difuso de constitucionalidade, havendo, inclusive, parte da doutrina processualista civil que defenda que eles podem ingressar em qualquer tipo de demanda, inclusive uma sem relevância ou matéria constitucional, perante qualquer grau de jurisdição (DIDIER JR., 2012, p. 418 ss.).

No que diz respeito à legislação, já há previsão que permite a relatores de processos subjetivos em apreciação nos tribunais admitir o ingresso de amici curiae ( $\S 3^{\circ}$ do art. 482 do (PC). 


\subsection{Audiências Públicas}

Impõe-se observar, outrossim, que as audiências públicas se tornaram um importante recurso institucional para ampliar o debate das questões apreciadas pelo STF. A previsão do $\S 1$ o do art. 9 da Lei de n. 9.868, ao autorizar a realização de eventos para “(...) ouvir depoimentos de pessoas com experiência e autoridade na matéria", possibilitou à Corte aumentar a abrangência dos argumentos trazidos ao seu conhecimento. Dispositivo análogo encontra-se no $\S 1^{\circ}$ do art. $6^{\circ}$ da Lei $n^{\circ}$ 9.882/99, aplicável às Arguições de Descumprimento de Preceito Fundamental (ADPFs).

Assinale-se, outrossim, a possibilidade do relator, em ações de controle abstrato, determinar o esclarecimento de matéria ou situação de fato ou de notória insuficiência das informações existentes nos autos, requisitar informações adicionais, nos termos do $\S 1^{\circ}$ do art. 9 da Lei de n. 9.868/99 e do $\S 1^{\circ}$ do art. 6 da Lei de n. 9.882/99. Vale mencionar, igualmente, o permissivo legal que autoriza o relator, nesses mesmos casos, a designar perito ou comissão de peritos para que emita parecer sobre questão relevante para o caso, ex ui do $\S 1^{\circ}$ do art. 9 da Lei de n. $9.868 / 99$ e do $\S 1^{\circ}$ do art. 6 da Lei de n. 9.882/99.

Por fim, é importante indicar que, mesmo em controle difuso de constitucionalidade, nos processos dotados de repercussão geral, é lícito ao relator admitir a manifestação de terceiros no processo, nos termos do regimento interno do STF e do $\S 6^{\circ}$ do art. 543-A do CPC.

É possível citar parte da literatura que acusa o Supremo de, ao decidir, não levar em conta as opiniões trazidas em sede de audiência pública e que aponta tais eventos como uma vã busca da Corte por legitimidade democrática.

Sob essa ótica, Virgílio Afonso da Silva (2012, pp. 28ss.), em seu texto Schiedsrichter und Spieler. Die Rolle des Oberstes Brasilianischen Gerichtshofs (STF) im Prozess der Demokratisierung in Brasilien, publicado no livro Verfassung und Verfassungsgericht? Deutschland und Brasilien im Vergleich, aponta algumas das causas do sucesso do ativismo do STF, dentre as quais se encontram algumas características do legislativo brasileiro. No que concerne às audiências públicas (öffentliche Anhörungen), o autor foca a inutilidade das audiências, conquanto, simultaneamente, elas sejam desfiladas, tal qual em uma parada, como uma das provas de legitimação democrática do Tribunal. Afonso DA SILVA chama esse 
fenômeno, por ele identificado, de estratégia de autolegitimação (Strategie zur Selbstlegitimierung).

Essa forte crítica parece ser minoritária na doutrina constitucional, que, de fato, indica a institucionalização das audiências públicas como um importante instrumento de democratização do controle de constitucionalidade, que é, por natureza, contra-majoritário e, justamente por isso, prócer e custódio de onerosos munera.

\subsection{Associação de associação e perda de representação no Congresso pelo Partido Político}

No passado, o STF negava a uma associação de associação o direito de ajuizar ação em sede de controle concentrado de constitucionalidade. Na ADI 591, por exemplo, negouse, à Associação dos Delegados de Polícia do Brasil (ADEPOL), a possibilidade de propor ação direta de inconstitucionalidade.

Entretanto, a Corte modificou seu entendimento, a fim de consolidar a visão de que associação de associações é, nos termos do art. 103 da CF, entidade de classe, o que faz com que tenha legitimidade para provocar o STF em controle abstrato de normas. A distinção que outrora se fazia, hoje já não é feita.

De maneira análoga, o STF entendeu, durante muito tempo, que a perda superveniente de representação no Congresso Nacional implicava a perda superveniente de objeto de ação direta proposta pelo correspondente partido político. Na prática, isso retirava do STF a possibilidade de apreciar questões de alta relevância constitucional. Ademais, comprovava a postura, um tanto prosaica, da Corte de aplicar categorias do processo civil tradicional, ao controle abstrato de normas. Com efeito, aplicavam-se institutos jurídicos como as condições da ação para suscitar uma suposta ilegitimidade ad causam superveniente.

Esse raciocínio, hoje superado, ignorava o papel precípuo desempenhado por um órgão de cúpula que exerce a Jurisdição Constitucional. Declaram-se inconstitucionais as normas que forem incompatíveis com a Constituição para garantir a supremacia desta. À luz disso, pouco importa se um dado partido detém ou não representação no Congresso Nacional. Uma vez proposta ação, e, preenchendo-se, contemporaneamente, os pressupostos do ajuizamento, o procedimento quase que deixa de ter partes. 
A guarda da Constituição não é matéria afeta a um ou outro protagonista social, mas sim à sociedade enquanto tal.

Com efeito, nos dois exemplos dados, a flexibilização, por parte do STF, dos requisitos impostos aos legitimados para ajuizar ação de controle abstrato de normas importa uma abertura procedimental desse mesmo controle.

\subsection{Novos paradigmas: o fim da pertinência temática e a legitimidade universal na ADPF?}

No sentido do que vem sendo realizado na judicatura do STF, é possível citar duas mudanças, ainda não implementadas, capazes de promover uma importante virada no controle de constitucionalidade exercido pela Corte. Trata-se do fim da pertinência temática e da implementação de legitimidade universal para a propositura de ADPF.

No primeiro caso, busca-se pôr fim à exigência criada jurisprudencialmente segundo a qual certos legitimados do rol do art. 103 da CF precisam provar ligação entre o ato normativo impugnado e a posição social ou jurídica que ocupam. Dessarte, cabe, por exemplo, ao Governador de Estado evidenciar que um ato normativo eventualmente impugnado por ele está a afetar, de alguma forma, o estado de que é governador. Do mesmo modo, a entidade de classe que propõe ADI, ADC ou ADPF está compelida a exibir a relação de pertença entre o ato objeto de controle e a atividade exercida pelos seus associados, ou mesmo, alguma relação ponderável com a área em que atua.

A exigência de pertinência temática não se encontra prevista na Constituição Federal e surgiu por meio de criação pretoriana. Esse requisito, que limita o acesso dos legitimados constitucionais ao STF, não passou imune a críticas. Hodiernamente, com a franca propensão do controle de normas a objetivar-se, é forçoso concluir que a relação do requerente e do ato impugnado deveria ser de somenos ou nenhuma importância (MENDES, 2012, p. 697ss.).

No que é relativo à legitimação universal para propor ADPF, trata-se de tentativa de autorizar “(...) qualquer pessoa lesada ou ameaçada por ato do Poder Público a propor Arguição de Descumprimento de Preceito Fundamental - ADPF." (MENDES, 2011, p. 10). Tentativa semelhante foi feita quando da aprovação original da lei da ADPF. Na 
oportunidade, todavia, o presidente vetou o inciso II do art. 2ㅇ da lei, restringindo o rol de legitimados àqueles que podem propor ADI.

A ideia de colocar essa proposta em prática continua viva. O projeto de Lei de $\mathrm{n}$. 6.543/06 tenta, exatamente, conceder a todo cidadão o direito de provocar, diretamente, o STF, para ver sanada eventual lesão inconstitucional de desconformidade com a Constituição. Resguardar-se-ia, ao Supremo, a possibilidade de analisar, ou não, os casos que, eventualmente, fossem levados à Corte, aplicando, nesse particular, o instituto da repercussão geral como forma de discernir entre eles.

As duas propostas revelam formas atualmente em discussão, de provocar uma ainda maior abertura procedimental da Jurisdição Constitucional como levada a efeito pelo STF.

Cumpre esclarecer que essa postura da Corte tem-se manifestado em diferentes esferas, o que demonstra a preocupação, cada vez maior do Tribunal, de garantir a supremacia da Constituição Federal e de impedir que minudências ou filigranas processuais impeçam a resolução de uma dada questão que perpassa a Lei Maior. A fungibilidade e a instrumentalidade afiguram-se presentes quando do debate acerca dessas questões.

\section{Abertura procedimental na suprema corte americana}

A fim de fornecer um exemplo de abertura procedimental ocorrida na Supreme Court, escolheu-se por mostrar a evolução do pensamento da Corte acerca do conceito de mootness, que equivale, em larga medida, ao que é chamado, no direito brasileiro, de "perda de objeto". Se se recorda que, na Suprema Corte americana, a atuação dos juízes apenas pode dar-se em "cases and controversies", então seria fácil concluir que a perda de objeto obstaria, de maneira absoluta, a apreciação de uma dada questão pela Corte. Porém, não é isso que ocorre.

Da "case and controversy clause", prevista no Article III, Section 2, Clause 1, da Constituição americana, a Suprema Corte entende emanarem limites ao poder de Judicial Review. Em especial, não cabe à Corte rever atos que não estejam, ainda que com base nos implied powers, sujeitos à competência das Cortes Federais ou que não envolvam algum dano ou prejuízo direto às partes envolvidas. 
Daí invocar-se, em casos como DeFunis v. Odegaard, 416 U.S. 312 (1974), a alegação de mootness. Nesse julgado, um jovem ao qual fora negado acesso a uma Faculdade de Direito (Law School), pleiteava o direito de ingresso. Contudo, posteriormente, o jovem foi admitido e, quando da iminência da decisão que seria tomada, já estava prestes a graduar-se.

Esse tipo de exigência, contudo, vem sendo relativizado há décadas (SCHULTZ; VILE; DEARDORFF, 2010). Em passagem célebre, o JUSTICE BLACKMUN, relator de Roe v. Wade, valendo-se de alguns precedentes, estabeleceu que, embora naquele caso já não houvesse qualquer remédio que o Tribunal pudesse prover, havia uma tendência de casos como aquele ocorrerem novamente. Assim, cunhou-se o termo "capable of repetition, yet evading review". Roe, mulher que ingressou contra o Texas para ver valer seu direito de privacidade, que tinha como um de seus corolários, segundo a Supreme Court, o direito ao aborto, já dera à luz um filho. Logo, nenhuma decisão prolatada pela Corte poderia desfazer isso. Contudo, a possibilidade de repetição de casos como aquele foi justificativa bastante para que, naquela ocasião, o Tribunal americano emitisse um pronunciamento sobre a tese jurídica sob exame.

Na opinion of the Court, o JUSTICE BLACKMUN asseverou que:

The normal 266-day human gestation period is so short that the pregnancy will come to term before the usual appellate process is complete. If that termination makes a case moot, pregnancy litigation seldom will survive much beyond the trial stage, and appellate review will be effectively denied. Our law should not be that rigid. (Roe v. Wade, 410 U.S. 113 (1973))

Dentre outros casos, em 2000, a Corte rejeitou, novamente, a alegação de mootness, ao apreciar a prejudicial suscitada em Friends of the Earth, Inc. v. Laidlaw Environmental Services, Inc., 528 U.S. 167 (2000). Fixou-se o entendimento de não é necessário provar um dano atual e específico para que o caso não termine por ser moot.

Esses rápidos exemplos explicitam a tendência da Suprema Corte americana, que tradicionalmente se apega ao fato de apenas ter competência para julgar casos concretos, de fixar-se, progressivamente, na importância da questão a ser analisada, sem tanto apego ao formalismo procedimental, o que implica privilegiar a questão a ser decidida, em detrimento da estima à mera forma. 


\section{Abertura procedimental no Tribunal Constitucional Federal Alemão (Bundesverfassungsgericht)}

Com o fito de exemplificar um instituto que vem sofrendo relativização, a bem da abertura procedimental, escolheu-se o Rechtsschutzbedürfnis. Trata-se, na Jurisdição Ordinária (ordentliche Gerichtsbarkeit), de uma condição da ação, muito semelhante, por sinal, à "necessidade", que é parte integrante do interesse de agir. Em alemão, diz-se que o Rechtsschutzbedürfnis - que significa, literalmente, "necessidade de tutela ou proteção" jurídica - é um pressuposto de admissibilidade (Zulässigkeitsvoraussetzung) para as demandas (Klagen) em geral (ROSENBERG; SCHWAB; GOTTWALD, 2011, p. 491ss.).

Outrossim, quando, por exemplo, da propositura de uma Verfassungsbeschwerde 2 perante o Tribunal Constitucional Federal (Bundesverfassungsgericht) ${ }^{3}$, deve-se preencher esse requisito (SCHMIDT, 2010).

Em sinal de abertura procedimental, nos casos de violação/intervenção (Eingriff) em direitos fundamentais dotados de especial significado (BVerfGE 69, 315 (341); 74, 102 (115)); ou quando a intervenção foi particularmente gravosa (BVerfGE 96, 288 (300); 98, 169 (197 f.); 100, 104 (125)); se há uma permanência dos efeitos danosos (BVerfGE 85, 36 (53); BVerfGE 91, 125 (133); BVerfGE 99, 129 (138)); ou, ainda, se há um perigo de reiteração (Wiederholungsgefahr) (BVerfGE 52, 42 (51); 69, 257 (266); 103, 44 (58 f.)), o BVerfG relativiza a exigência do Rechtsschutzbedürfnis ou, mais tecnicamente, amplia a área de abrangência desse conceito. Isso significa que, alargando a hipótese de incidência, mais casos preencherão esse pré-requisito (SCHLAICH; KORIOTH, 2012, p. 256).

Não se deve concluir, a partir daí, que um número muito grande das Verfassungsbeschwerden passa pelo crivo da admissibilidade (Zulässigkeit) e da fundamentação (Begründung) ou procedência. Contudo, é sim possível extrair que o BVerfG

2 Este é um termo de difícil tradução. Literalmente, poder-se-ia traduzir por "reclamação constitucional". Alguns preferem a expressão "recurso constitucional". Contudo, a natureza jurídica da Verfassungsbeschwerde é de ação e não de recurso, na acepção técnico-processual do termo. Assinale-se, ainda, que tampouco se trata de incidente processual. De qualquer sorte, trata-se do instrumento jurídico que pode ser manejado por qualquer pessoa (jedermann) contra ato, comissivo ou omissivo, que viole, atual e diretamente (gegenwärtig und unmittelbar), direito fundamental ou direito equiparado a fundamental (grundrechtsgleiches Recht) (PIEROTH; SCHLINK, 2011, p. 309). A Verfassungsbeschwerde guarda semelhanças com o recurso de amparo do direito espanhol, ao qual ela é, até certo ponto e guardadas as devidas proporções, análoga.

3 Doravante, BVerfG. 
se revela cada vez mais preocupado com a possibilidade de decidir, de maneira clara e definitiva, questões constitucionais relevantes. Os casos concretos eventualmente suscitados podem ter algumas de suas peculiaridades ignoradas, se isso for instrumental para que a Corte emita pronunciamento importante.

Em 14 de julho de 1994, por exemplo, o primeiro Senado (erster Senat) do BVerfG decidiu ser constitucional a lei que proibia a veiculação, pela televisão, de procedimentos perante juízos ou tribunais. A decisão causou vasta polêmica doutrinária (MENZEL; MÜLLERTERPITZ, 2011, p. 673ss.). Na ocasião, uma das teses invocadas, contra a Verfassungsbeschwerde levada ao BVerfG foi de que não haveria, no caso do particular que a moveu, qualquer necessidade de tutela jurídica, já que o impedimento já ocorrera e era, faticamente, impossível voltar no tempo para que a filmagem de um julgamento já consumado fosse repetida e filmada. O perigo de reiteração ou repetição daquela situação foi a principal justificativa invocada pela Corte, que não teve problemas em, abstraindo do caso concreto, fixar uma tese constitucional que passaria a ter força vinculante daí em diante.

Leiam-se, a propósito, as seguintes passagens, oriundas de decisões da Corte alemã:

Durch die Beendigung der Verfahren vor dem Landgericht Berlin und vor dem Bundesverwaltungsgericht ist das Rechtsschutzbedürfnis der Beschwerdeführerin nicht entfallen. Es besteht trotz Erledigung des ursprünglichen Begehrens fort, weil die Frage, ob und in welchem Umfang die Zulassung von Fernsehaufnahmen in Gerichtsverfahren verfassungsrechtlich geboten ist, von erheblicher Bedeutung und vom Bundesverfassungsgericht noch nicht entschieden ist. Zudem hat die Beschwerdeführerin unter dem Gesichtspunkt der Wiederholungsgefahr ein anerkennenswertes Interesse an der Feststellung, ob die angegriffenen Verfügungen verfassungsgemäß waren (vgl. BVerfGE 91, 125 [133]). (BVerfGE 91, 125 (31))

Durch die Beendigung des Verfahrens gegen die Mehrzahl der Angeklagten ist das Rechtsschutzbedürfnis der Beschwerdeführer nicht entfallen. Das Rechtsschutzbedürfnis besteht trotz Erledigung des ursprünglichen Begehrens fort, wenn andernfalls die Klärung einer verfassungsrechtlichen Frage von grundsätzlicher Bedeutung unterbliebe, etwa weil die Sachentscheidung des Bundesverfassungsgerichts wegen der Art der Maßnahme oder des Geschehensablaufs nicht rechtzeitig ergehen kann, und wenn der gerügte Grundrechtseingriff besonders schwer wiegt; es besteht ferner dann fort, wenn eine Wiederholung der angegriffenen Maßnahme zu befürchten ist oder die gegenstandslos gewordene Maßnahme den Beschwerdeführer weiterhin beeinträchtigt (vgl. BVerfGE 49, 24 [52]; 81, 138 [140], m.w.N.; st. Rspr.). Diese Voraussetzungen sind hier gegeben. Die Frage, ob und in welchem Umfang die Rundfunkfreiheit Fernsehaufnahmen von Gerichtsverfahren rechtfertigt, ist von erheblicher Bedeutung und vom Bundesverfassungsgericht noch nicht 
entschieden. Außerdem haben die Beschwerdeführer auch unter dem Gesichtspunkt der Wiederholungsgefahr ein anerkennenswertes Interesse an der Feststellung, ob die angegriffene Anordnung des Vorsitzenden der Strafkammer verfassungsmäßig war. (BVerfGE 103, 44 (55))

Em 4 de fevereiro de 2005, por exemplo, o BVerfG lavrou decisão afastando alegações de ausência de Rechtsschutzbedürfnis. Na espécie, tinha-se um reclamante que ia ao Tribunal alegando que, durante uma busca e apreensão, feita sem ordem judicial, um policial tomara seu celular, verificando vários arquivos que nele estavam. Advogou-se que, já tendo havido a leitura dos dados contidos no celular, não havia mais necessidade de tutela jurídica, uma vez que nada seria capaz de desfazer o ocorrido.

O BVerfG entendeu que, ao lidar com profunda violação de direito fundamental (tiefgreifender Grundrechtseingriff), não há que se falar em perda da necessidade da tutela jurídica (cf. BVerfG 2 BvR 308/04. No mesmo sentido: BVerfG 2 BvR 515/91, bem como BVerfG 2 BVR 2233/04.).

Os excertos demonstram a preocupação do BVerfG em fixar teses jurídicas, a serem aplicadas de maneira geral, ainda que isso não venha a resolver o litígio concreto que, eventualmente, levou a matéria ao Tribunal.

\section{Conclusão}

Resumidamente, é possível reconhecer uma tendência da Jurisdição Constitucional, conforme desempenhada por órgãos de cúpula, de apegar-se menos a formalismos procedimentais. Os fatos, no caso da Alemanha e dos EUA, sugerem que isso tem como causa o esforço das Cortes de não afastarem a apreciação de teses jurídico-constitucionais tidas como de relevância coletiva, ainda que, casualmente, não se vislumbre mais, no caso concreto que motivou a remessa da questão à Corte, necessidade de intervenção judicial.

Por outro lado, no exemplo brasileiro, é possível enxergar forte vocação do controle de constitucionalidade, seja ele difuso ou abstrato, objetivar-se, isto é, deixa-se de lado, em proporção cada vez maior, as peculiaridades de um dado caso, para estabelecer precedentes normativos com força vinculante, a serem seguidos, na esteira do STF, pelas Cortes de todo o país.

Essas constatações não causam (ou não deveriam causar) surpresa. Na verdade, trata-se de decorrência natural da natureza objetiva do controle de normas. A uniformização 
da interpretação do texto constitucional exige a previsibilidade e clareza das decisões tomadas, de maneira centralizada, por órgãos de cúpula. Diz-se, até, há anos, que o controle de normas possui um procedimento sem partes (Verfahren ohne Beteiligte) (TRIEPEL, 1929, p. 17; 23; MENDES, 2012, p. 329). Se é assim, deve-se privilegiar o acesso ao Tribunal Constitucional.

HANS KELSEN, por exemplo, em seu célebre Referat sobre a natureza ou essência da Jurisdição Estatal ou Constitucional, afirmava que, preferível seria, embora pouco praticável, se se admitisse a actio popularis, ou seja, a legitimação universal, no controle de normas em face da Constituição. A defesa em favor dessa postura baseava-se no fato de que a ampliação dos legitimados impediria atos inconstitucionais - verdadeiros párias do ordenamento jurídico -, de manterem-se em vigência (KELSEN, 1929, p. 74; 87).

Muito tempo após KELSEN, é possível notar, com a predisposição instalada atualmente, de ampliar o âmbito da ADPF e da abertura procedimental já promovida no Brasil e no exterior, que, de fato, o jusfilósofo austríaco soube enxergar que, em um Estado pautado pela Constituição, não há espaço para diplomas legais que afrontem a sua supremacia hierárquica. Logo, quanto maior for o número de questões levadas à Corte, a qual detém a última palavra sobre a Constituição, tanto maior será a efetividade do texto constitucional.

\section{Referências}

AFONSO DA SILVA, Virgílio. "Schiedsrichter und Spieler. Die Rolle des Oberstes Brasilianischen Gerichtshofs (STF) im Prozess der Demokratisierung in Brasilien." In: AFONSO DA SILVA, Virgílio; SCHMIDT, Rainer (Hrsg.) Verfassung und Verfassungsgericht: Deutschland und Brasilien im Vergleich. Baden-Baden: Nomos, 2012.

DIDIER JR., Fredie. Curso de Processo Civil. Salvador: Juspodivm, vol. I, 2012.

KELSEN, Hans (1929). Wesen und Entwicklung der Staatsgerichtsbarkeit. (VVDStL, 5) Berlin u. Leipzig: Walter de Gruyter, 1929.

MENDES, Gilmar Ferreira. Arguição de Descumprimento de Preceito Fundamental. São Paulo: Saraiva, 2011.

MENDES, Gilmar Ferreira. Controle Abstrato de Constitucionalidade: ADI, ADC e ADO Comentários à Lei n. 9.868/99. 1ạed. (Série EDB). São Paulo: Saraiva, 2012. 
MENZEL, Jörg; MÜLLER-TERPITZ, Ralf. Verfassungsrechtsprechung. 2.Auf. Stuttgart: Mohr Siebeck, 2011.

PIEROTH, Bodo; SCHLINK, Bernhard. Grundrechte. Staatsrecht II. 27.Auf. München: C.F. Müller, 2011.

ROSENBERG, Leo; SCHWAB, Karl Heinz; GOTTWALD, Peter. Zivilprozessrecht. 17.Auf. München: C.H. Beck, 2011.

SCHLAICH, Klaus; KORIOTH, Stefan. Das Bundesverfassungsgericht: Stellung, Verfahren, Entscheidungen. München: C.H. Beck, 2012.

SCHMIDT, Thorsten Ingo. Verfassungsprozessrecht. München: C.H. Beck, 2010.

SCHULTZ, David; VILE, John R.; DEARDORFF, Michelle D. Constitutional Law in Contemporary America: vol. Two - Civil Rights and Liberties. Oxford: Oxford University Press, 2010.

TRIEPEL, Heinrich. Wesen und Entwicklung der Staatsgerichtsbarkeit. (VVDStL, 5) Berlin u. Leipzig: Walter de Gruyter, 1929.

Artigo recebido em 10/07/2012 e aprovado para publicação em 17/08/2012. 
